\title{
Phenolic content variability and its chromosome location in tritordeum
}

\author{
José F. Navas-Lopez, Francisco J. Ostos-Garrido, Almudena Castillo, Antonio Martín, \\ Maria J. Gimenez and Fernando Pistón*
}

Departamento de Mejora Genética Vegetal, Instituto de Agricultura Sostenible - Consejo Superior de Investigaciones Científicas, Córdoba, Spain

\section{Edited by:}

Jaime Prohens, Universitat

Politècnica de València, Spain

Reviewed by:

Jose M. Jimenez-Gomez, Max

Planck Institute for Plant Breeding,

Germany

Elena Benavente, Universidad

Politecnica de Madrid, Spain

\section{*Correspondence:}

Fernando Pistón, Departamento de Mejora Genética Vegetal, Instituto

de Agricultura Sostenible - Consejo

Superior de Investigaciones

Científicas, (IAS-CSIC), Alameda del

Obispo s/n, 14080 Córdoba, Spain

e-mail: fpiston@ias.csic.es
For humans, wheat is the most important source of calories, but it is also a source of antioxidant compounds that are involved in the prevention of chronic disease. Among the antioxidant compounds, phenolic acids have great potential to improve human health. In this paper we evaluate the effect of environmental and genetic factors on the phenolics content in the grain of a collection of tritordeums with different cytoplasm and chromosome substitutions. To this purpose, tritordeum flour was used for extraction of the free, conjugates and bound phenolic compounds. These phenolic compounds were identified and quantified by RP-HPLC and the results were analyzed by univariate and multivariate methods. This is the first study that describes the composition of phenolic acids of the amphiploid tritordeum. As in wheat, the predominant phenolic compound is ferulic acid. In tritordeum there is great variability for the content of phenolic compounds and the main factor which determines its content is the genotype followed by the environment, in this case included in the year factor. Phenolic acid content is associated with the substitution of chromosome DS1D $\left(1 \mathrm{H}^{\mathrm{ch}}\right)$ and DS2D $\left(2 \mathrm{H}^{\mathrm{ch}}\right)$, and the translocation $1 \mathrm{RS} / 1 \mathrm{BL}$ in tritordeum. The results show that there is high potential for further improving the quality and quantity of phenolics in tritordeum because this amphiploid shows high variability for the content of phenolic compounds.

Keywords: plant breeding, antioxidant, healthy, variability, nutritive, chromosome sustitution, wheat, flour quality

\section{INTRODUCTION}

Cereals, particularly wheat, are the most important food source for human. Numerous studies have demonstrated the key role of whole grains in human health benefits, since they are known to be protective against chronic diseases. These data provide further support for recommendations to increase consumption of whole grains and its use as healthy products (Marquardt et al., 2004; Flight and Clifton, 2006; de Munter et al., 2007; Jonnalagadda et al., 2011). A wide range of phytochemicals with antioxidant activity present in cereal grains has been indicated to be responsible for these health protection qualities. These compounds belong to chemical groups such as polyphenols, carotenoids, and plant sterols. Among the different antioxidants present in wheat, phenolic compounds seem to have the greatest potential of being beneficial to health (Beta et al., 2005; Mpofu et al., 2006).

Phenolic acids are the most frequent phenolic compounds in cereals; these can be found as free, bound and conjugated forms. Most phenolic acids are bound by ester-linked to the cell wall polymers (Irakli et al., 2012). The main phenolic acids in wheat are ferulic and $\rho$-coumaric acids, both associated with cell-wall constituents (Zhou et al., 2004, 2005; Okarter et al., 2010). It has been described that factors such as the genotype, environmental factors and genotype-environment interactions can influence total phenolic compounds content and the relative content of different phenolics fractions. Yu and Zhou (2005) described the effect of the location, on the content of phenolic compounds; Moore et al. (2006) observed significant correlations between temperature stress or solar radiation and some antioxidant contents. Furthermore, Fernandez-Orozco et al. (2010) showed that environmental factors did not equally affect to all phenolic compounds fractions, the fractions of free phenolic compounds and conjugates being more affected than the fraction of bound phenolics.

In addition, the content of phenolic compounds is affected by the genotype and the genotype $\mathrm{x}$ environment interaction. The results of Mpofu et al. (2006) showed that environmental effects on the content of phenolic compounds were considerably larger than the genotype effect, and genotype $x$ environment interaction was small for all parameters as compared to both main factors . The study of Fernandez-Orozco et al. (2010) also showed that the environmental effects were larger than genotypic differences, especially for the low abundance of free and conjugated phenolic acid fractions. Li et al. (2008) reported differences in phenolic content between varieties, and they suggested that it may be possible to develop varieties with a high content of phenolic acids. The results of Shewry et al. (2010) corroborated previous reports and demonstrated that heritable variation in the content of bioactive components can be exploited by breeders to develop new cultivars with enhanced health benefits. Triticeae wild species might also be a valuable source of variability, but transferring this variability to cultivated species presents multiple problems. That is not the case of the wild species Hordeum chilense Roem. et Schultz. whose variability for traits of interest may be used in both durum and bread wheat breeding using 
the amphiploids called tritordeums ( $\times$ Tritordeum Ascherson et Graebner) (Martin and Sanchez-Mongelaguna, 1982; Martín et al., 1998, 1999).

Moreover, other qualities of tritordeum confer on it the potential to be part of a healthy diet and it has recently been introduced to the market as an alternative food cereal (www. tritordeum.com). For example, tritordeum has a high content of carotenoids, such as lutein, which has been associated with prevention against different diseases (Atienza et al., 2007; Mellado-Ortega and Hornero-Méndez, 2012). To the present, little is known about the content and variability of phenolic compounds, especially phenolic acids of tritordeum. In addition, factors affecting the content of phenolic compounds have not been determined and it is not known whether they are the same as those involved in the content of phenolic compounds in wheat. Furthermore, little is known about the genetic and chromosomal location of the trait of high/low content of phenolic compounds. In order to carry out an efficient improvement of this character to increase health benefits, more information on the factors affecting phenolic content needs to be collected.

The aim of the present work was to evaluate the whole grain phenolic acids content of accessions of hexaploid tritordeum and to assess the effect of the environment and some genetic factors such as the presence of barley or wheat cytoplasm; substitution of chromosomes $1 \mathrm{H}^{\mathrm{ch}}, 2 \mathrm{H}^{\mathrm{ch}}$, and $5 \mathrm{H}^{\mathrm{ch}}$; and the $1 \mathrm{RS} / 1 \mathrm{BL}$ translocation, on phenolic acid content.

\section{MATERIALS AND METHODS}

\subsection{PLANT MATERIAL}

Thirty seven accessions of hexaploid tritordeum originating from different stages of the tritordeum breeding program were evaluated (Table 1). The previous genotyping of the tritordeum lines (Castillo et al., 2013) allowed their characterization. Different groups were identified according their genomic constitution (1) cytoplasm, (2) chromosome substitutions, and (3) $1 \mathrm{RS} / 1 \mathrm{BL}$ translocation. Tritordeum grains were ground using a cyclonic mill (Ciclotec lab mill, Tecator) with $1 \mathrm{~mm}$ mesh to produce wholemeal flour. Samples were stored at $4^{\circ} \mathrm{C}$ until analysis.

\subsection{PHENOLIC COMPOUNDS EXTRACTION \\ 2.2.1. Extraction of free phenolics}

Free phenolics (and also bound and conjugate phenolics) were extracted using the method previously reported by Okarter et al. (2010) with some modifications. One hundred milligram of wholemeal flour was blended with $670 \mu \mathrm{l}$ of $80 \%$ chilled acetone in $2 \mathrm{~mL}$ tube. Inside of the tube we added a $5 \mathrm{~mm}$ stainless steel ball to facilitate the mixing in a Retsch MM200 ball mill for $1 \mathrm{~min}$ at $60 \%$ of power. The mixture was centrifuged at $2500 \times \mathrm{g}$ for $10 \mathrm{~min}$ The supernatant was removed and the remaining pellet was extracted two times more with $80 \%$ chilled acetone following the same process. The supernatants were pooled and evaporated in a Speed Vac vacuum centrifuge (Savant) to dryness. The solution was then reconstituted with methanol/hydrochloric acid $(1 \mathrm{M} ; 85: 15, \mathrm{v} / \mathrm{v})$, filtered through a $0.45 \mu \mathrm{m}$ filter, and stored at $-20^{\circ} \mathrm{C}$ until analysis.
Table 1 | Tritordeum collection used in this study.

\begin{tabular}{|c|c|c|c|c|}
\hline Line & Year & Cytoplasm & 1RS/1BL & Substitutions \\
\hline 223 & $10 ; 11 ; 12$ & H. chilense & $\mathrm{N}$ & N \\
\hline 294 & $10 ; 11 ; 12$ & Wheat & $\mathrm{N}$ & $\mathrm{DS} 1 \mathrm{D}\left(1 \mathrm{H}^{\mathrm{ch}}\right)$ \\
\hline 295 & $10 ; 11 ; 12$ & H. chilense & $\mathrm{N}$ & N \\
\hline 296 & $10 ; 11 ; 12$ & Wheat & $\mathrm{N}$ & $\mathrm{N}$ \\
\hline 320 & $10 ; 11 ; 12$ & H. chilense & $\mathrm{N}$ & $\mathrm{N}$ \\
\hline 322 & $10 ; 11 ; 12$ & H. chilense & $\mathrm{N}$ & $\mathrm{N}$ \\
\hline 323 & $10 ; 11 ; 12$ & H. chilense & $\mathrm{N}$ & $\mathrm{N}$ \\
\hline 324 & $10 ; 11 ; 12$ & H. chilense & $\mathrm{N}$ & $\mathrm{N}$ \\
\hline 325 & $10 ; 11 ; 12$ & H. chilense & $\mathrm{N}$ & $\mathrm{N}$ \\
\hline 326 & $10 ; 11 ; 12$ & H. chilense & $\mathrm{N}$ & $\mathrm{N}$ \\
\hline 327 & $10 ; 11 ; 12$ & H. chilense & $\mathrm{N}$ & $\mathrm{N}$ \\
\hline 328 & $10 ; 11 ; 12$ & Wheat & $\mathrm{N}$ & $\mathrm{DS} 1 \mathrm{D}\left(1 \mathrm{H}^{\mathrm{ch}}\right)$ \\
\hline 400 & $10 ; 11 ; 12$ & Wheat & $\mathrm{N}$ & $\mathrm{DS} 2 \mathrm{D}\left(2 \mathrm{H}^{\mathrm{ch}}\right)$ \\
\hline 409 & $10 ; 11 ; 12$ & Wheat & $\mathrm{R}$ & $\mathrm{DS} 5 \mathrm{D}\left(5 \mathrm{H}^{\mathrm{ch}}\right)$ \\
\hline 410 & $10 ; 11 ; 12$ & H. chilense & $\mathrm{R}$ & N \\
\hline 411 & $10 ; 11 ; 12$ & H. chilense & $\mathrm{R}$ & $\mathrm{N}$ \\
\hline 412 & $10 ; 11 ; 12$ & H. chilense & $\mathrm{N}$ & $\mathrm{N}$ \\
\hline 413 & $10 ; 11 ; 12$ & H. chilense & $\mathrm{R}$ & $\mathrm{N}$ \\
\hline 414 & $10 ; 11 ; 12$ & Wheat & $\mathrm{R}$ & $\mathrm{N}$ \\
\hline 415 & $10 ; 11 ; 12$ & Wheat & $\mathrm{R}$ & $\mathrm{DS} 2 \mathrm{D}\left(2 \mathrm{H}^{\mathrm{ch}}\right)$ \\
\hline 416 & $10 ; 11 ; 12$ & Wheat & $\mathrm{R}$ & $\mathrm{DS} 2 \mathrm{D}\left(2 \mathrm{H}^{\mathrm{ch}}\right)$ \\
\hline 417 & $10 ; 11 ; 12$ & H. chilense & $\mathrm{R}$ & $\mathrm{DS} 2 \mathrm{D}\left(2 \mathrm{H}^{\mathrm{ch}}\right)$ \\
\hline 418 & $10 ; 11 ; 12$ & NA & $\mathrm{N}$ & N \\
\hline 419 & $10 ; 11 ; 12$ & Wheat & $\mathrm{N}$ & $\mathrm{N}$ \\
\hline 421 & $10 ; 11 ; 12$ & Wheat & $\mathrm{R}$ & $\operatorname{DS} 2 \mathrm{D}\left(2 \mathrm{H}^{\mathrm{ch}}\right) ; \mathrm{DS} 5 \mathrm{D}\left(5 \mathrm{H}^{\mathrm{ch}}\right)$ \\
\hline 422 & $10 ; 11 ; 12$ & Wheat & $\mathrm{N}$ & $\mathrm{N}$ \\
\hline 423 & $10 ; 11 ; 12$ & H. chilense & $\mathrm{N}$ & $\mathrm{N}$ \\
\hline 424 & $10 ; 11 ; 12$ & Wheat & $\mathrm{R}$ & $\operatorname{DS} 2 \mathrm{D}\left(2 \mathrm{H}^{\mathrm{ch}}\right) ; \mathrm{DS} 5 \mathrm{D}\left(5 \mathrm{H}^{\mathrm{ch}}\right)$ \\
\hline 425 & $10 ; 11 ; 12$ & Wheat & $\mathrm{R}$ & $\operatorname{DS} 2 \mathrm{D}\left(2 \mathrm{H}^{\mathrm{ch}}\right) ; \mathrm{DS} 5 \mathrm{D}\left(5 \mathrm{H}^{\mathrm{ch}}\right)$ \\
\hline 427 & $10 ; 11 ; 12$ & Wheat & $\mathrm{N}$ & $\mathrm{N}$ \\
\hline 429 & $10 ; 11 ; 12$ & Wheat & $\mathrm{R}$ & N \\
\hline 430 & $10 ; 11 ; 12$ & H. chilense & $\mathrm{R}$ & $\mathrm{DS} 5 \mathrm{D}\left(5 \mathrm{H}^{\mathrm{ch}}\right)$ \\
\hline 431 & $10 ; 11 ; 12$ & H. chilense & $\mathrm{N}$ & $\mathrm{DS} 5 \mathrm{D}\left(5 \mathrm{H}^{\mathrm{ch}}\right)$ \\
\hline 432 & $10 ; 11 ; 12$ & H. chilense & $\mathrm{R}$ & N \\
\hline 436 & $10 ; 11 ; 12$ & H. chilense & $\mathrm{N}$ & $\mathrm{DS} 5 \mathrm{D}\left(5 \mathrm{H}^{\mathrm{ch}}\right)$ \\
\hline 621 & $10 ; 11 ; 12$ & NA & NA & NA \\
\hline 631 & $10 ; 11 ; 12$ & Wheat & $\mathrm{N}$ & $\mathrm{N}$ \\
\hline
\end{tabular}

10;11;12, years 2010, 2011 and 2012 respectively; $N$, no translocation or no substitutions; $R, 1 R S / 1 B L$ translocation; NA, no available.

\subsubsection{Extraction of bound phenolics}

Insoluble-bound phenolics were extracted from the residue after the free phenolics extraction. The residue was then washed three times with distilled water to remove the water soluble sugars which may gelate and hinder the extraction of bound phenolics. After washing, the residual pellet was digested with $1.5 \mathrm{ml}$ of a $2 \mathrm{~N}$ sodium hydroxide solution. The mixture was blended in a Retsch MM200 ball mill for $1 \mathrm{~min}$ at $60 \%$ of power and incubated for $1 \mathrm{~h}$ at room temperature under gentle shaking in darkness. Both the sodium hydroxide and the mixture of sodium hydroxide and the pellet were degassed with nitrogen. After digestion, the tubes were centrifuged for $2 \mathrm{~min}$ at $8000 \times \mathrm{g}$ and each supernatant was transferred to a new tube. The digestion was stopped with fumant 

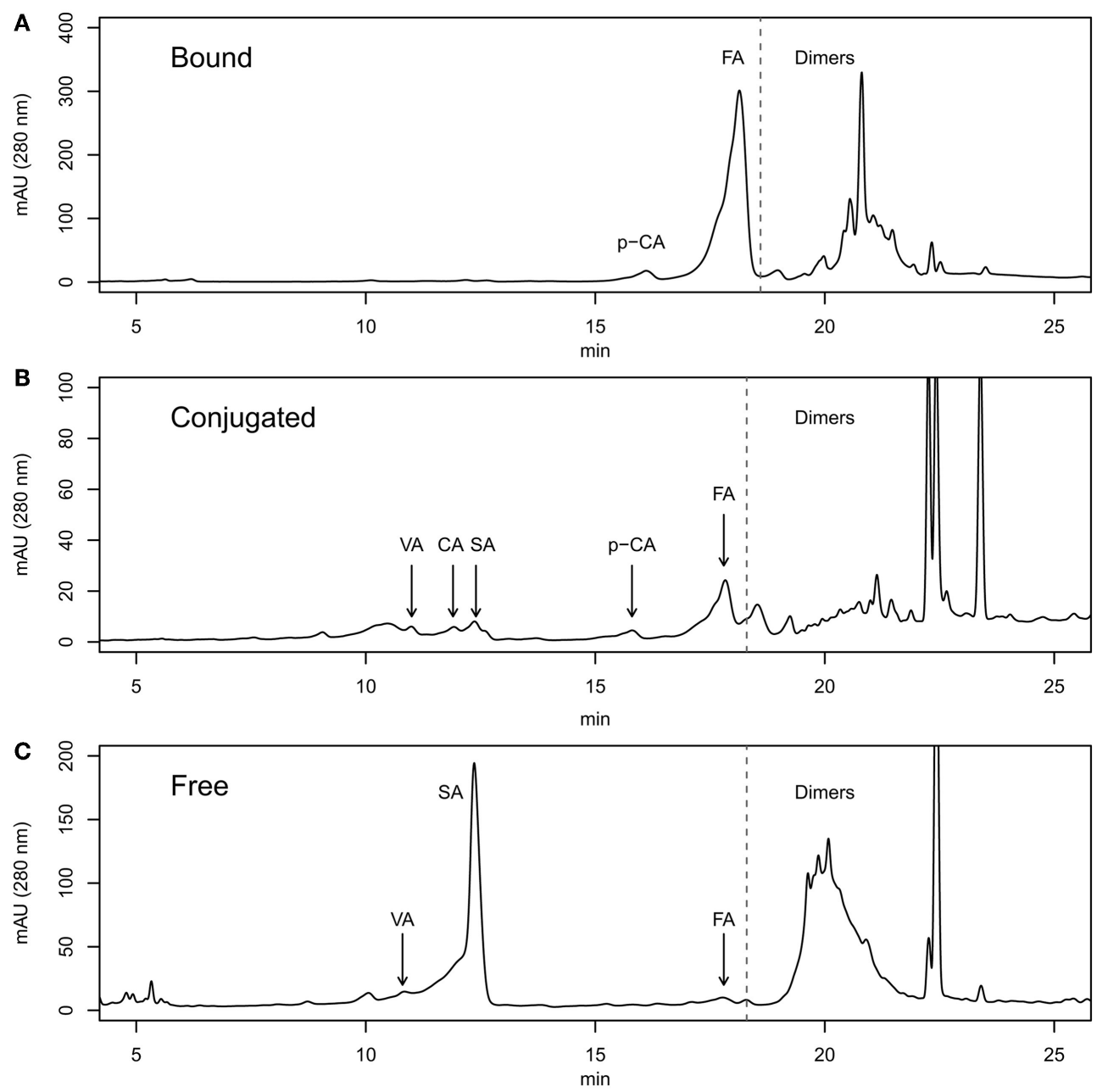

FIGURE 1 | RP-HPLC chromatograms of the bound (A), conjugated (B), and free (C) phenolics fractions from tritordeum grain.

chloride acid (75\%) to reach a $\mathrm{pH} 2$. We extracted the phenolics by adding $670 \mu \mathrm{l}$ of ethyl acetate, mixing by vortex for $1 \mathrm{~min}$ and centrifuging for $10 \mathrm{~min}$ at $7000 \times \mathrm{g}$. The supernatant was transferred to a clean tube. This process was repeated three times and the supernatants pooled. The ethyl acetate was evaporated in a Speed Vac vacuum centrifuge (Savant). The solution was then reconstituted with mehtanol/hydrochloric acid ( $1 \mathrm{M} ; 85: 15$, $\mathrm{v} / \mathrm{v})$, filtered through a $0.45 \mu \mathrm{m}$ filter, and stored at $-20^{\circ} \mathrm{C}$ until analysis.

\subsubsection{Extraction of soluble-conjugated phenolic compounds}

Soluble-conjugated phenolics were extracted from half volume of free phenolics extracts using the method reported above for the bound phenolics with some minor modifications. To the residue from evaporation of the acetone of half volume of free phenolics extracts, we added $1.5 \mathrm{ml}$ of $2 \mathrm{~N}$ sodium hydroxide and from this step we followed the same process like in the extraction of bound phenolics.

\subsection{HPLC METHOD}

The phenolics extracts $(100 \mu \mathrm{l})$ were applied to a Eclipse XDB-C18 reverse phase analytical column $(4.6 \times 150 \mathrm{~mm}$,
$5 \mu \mathrm{m}$ particle size; Agilent Technologies) using a 1200 Series Quaternary LC System liquid chromatograph (Agilent Technologies) with a DAD UV-V detector. We eluted the phenolic compounds using as solvent A a mix of water and $0.01 \%$ trifluoroacetic (TFA), and as solvent $\mathrm{B}$ a mix of acetonitrile (ACN) and $0.01 \%$ of TFA, according to the following method: $1 \mathrm{ml} \mathrm{min} \mathrm{m}^{-1}$, and a gradient from $7 \%$ to $16 \%$ of solvent $\mathrm{B}$ (to $100 \%$ with solvent A) over $22.5 \mathrm{~min}$ followed by a $65 \%$ of solvent $\mathrm{B}$ over $5 \mathrm{~min}$ to wash the column. Absorbance was monitored with the DAD UV-V module at $280 \mathrm{~nm}$.

\subsection{EXPERIMENTAL DESIGN AND STATISTICAL ANALYSIS}

All analyses were conducted with the statistical software R version 2.12.1 (R Development Core Team, 2012). The experimental design was a completely randomized design replicated for 3 years (2010-2012) with a $2 \mathrm{~m}^{2}$ plots. Data were adjusted to a lineal model with the function $l m$ and factors effects were checked by a analysis of variance with the function anova. The lineal models were adjusted with the factors "Year," "Line," "Substitution," "1RS/1BL" and "Cytoplasm" (see models formula in section 3). Factor "Year" has three levels (years 2010, 2011, and 2012), factor "Line" has 37 (see Table 3), factor "Substitution" has five 
Table 2 | Table with the mean percentage and standard deviation of each phenolic acid relative to the total phenolic compounds.

\begin{tabular}{|c|c|c|}
\hline Phenolic compound & Mean (\%) & $S D$ \\
\hline Bound ferulic acid & 68.90 & 6.50 \\
\hline Bound vanillic acid & 0.00 & 0.00 \\
\hline Bound $\rho$-coumaric acid & 3.50 & 1.10 \\
\hline Bound syringic acid & 0.10 & 0.10 \\
\hline Bound caffeic acid & 0.10 & 0.10 \\
\hline Bound dimers & 6.70 & 0.80 \\
\hline Free ferulic acid & 1.30 & 1.00 \\
\hline Free vanillic acid & 0.80 & 0.40 \\
\hline Free $\rho$-coumaric acid & 0.30 & 1.10 \\
\hline Free syringic acid & 15.60 & 6.90 \\
\hline Free caffeic acid & 0.40 & 1.60 \\
\hline Free dimers & 7.60 & 1.50 \\
\hline Conjugated ferulic acid & 6.20 & 2.10 \\
\hline Conjugated vanillic acid & 0.70 & 0.20 \\
\hline Conjugated $\rho$-coumaric acid & 0.70 & 0.60 \\
\hline Conjugated syringic acid & 0.90 & 0.30 \\
\hline Conjugated caffeic acid & 0.50 & 0.30 \\
\hline Conjugated dimers & 1.90 & 0.30 \\
\hline Total ferulic acid & 76.40 & 6.40 \\
\hline Total vanillic acid & 1.50 & 0.60 \\
\hline Total $\rho$-coumaric acid & 4.50 & 1.70 \\
\hline Total syringic acid & 16.60 & 6.90 \\
\hline Total caffeic acid & 1.00 & 1.60 \\
\hline Total bound & 72.60 & 6.60 \\
\hline Total free & 18.50 & 6.60 \\
\hline Total conjugated & 8.90 & 2.90 \\
\hline Total dimers & 16.20 & 2.00 \\
\hline
\end{tabular}

To calculate the mean and standard deviation values shown in the table we used all the lines and years. sd, standard deviation; dimers, dimers of phenolic compound; "total" is the sum of bound, free and conjugated phenolics. Percentages are calculate using absorbance data.

SD: standard deviation en \%.

levels (DS1D $\left(1 \mathrm{H}^{\mathrm{ch}}\right), \operatorname{DS} 2 \mathrm{D}\left(2 \mathrm{H}^{\mathrm{ch}}\right), \operatorname{DS} 5 \mathrm{D}\left(5 \mathrm{H}^{\mathrm{ch}}\right), \operatorname{DS} 2 \mathrm{D}\left(2 \mathrm{H}^{\mathrm{ch}}\right)$ $\operatorname{DS} 5 \mathrm{D}\left(5 \mathrm{H}^{\mathrm{ch}}\right)$ and $\left.\mathrm{N}\right)$, "1RS/1BL" has two levels (R (1RS/BL translocation) and N (no translocation)) and "Cytoplasm" has two levels (cytoplasm from $H$. chilense and from Wheat).

The normality and heteroscedasticity assumptions were tested by plotting the residuals versus the predicted values and Q-Q plots. In the cases where the conditions of data normality and homogeneity of variances were violated the Box-Cox transformation was applied (function powerTransform, package car) (Fox and Weisberg, 2011). The differences between tritordeum lines were assessed using post hoc multiple-comparison test (function glht, package multcomp) (Hothorn et al., 2008). The method used for multiple-comparison was a Tukey contrast with a $p$-values adjustment type free (see package multcomp for more information).

To identify the relative importance of each factor in the total set of data, we performed a multivariate analysis of variance (MANOVA) with the function $\mathrm{lm}$. The multivariate models were adjusted with the factors "Year," "Line," "Substitution,"
"1RS/1BL" and "Cytoplasm" (see models formula in section 3). As an exploratory graphic, we generated a Principal Components Analysis (PCA) to demonstrate trends of tritordeum lines in relation to the variables studied using the function PCA (package FactoMineR) (Husson et al., 2013). The package maptools was used to avoid the label overlapping in the ordination plot (Lewin-Koh et al., 2012).

\section{RESULTS}

\subsection{IDENTIFICATION OF PHENOLIC COMPOUNDS}

For identification of phenolic compounds by RP-HPLC we used pure compounds from SIGMA-ALDRICH (http://www. sigmaaldrich.com/). The pure compounds ferulic acid (FA, cat\# 46278), $\rho$-coumaric acid (pCA, cat\# C9008), caffeic acid(CA, cat\# C0625), vanillic acid (VA, cat\# 94770) and syringic acid (SA, cat\# S6881) were dissolved in methanol at a concentration of $1 \mathrm{mg} / \mathrm{ml}$ and injected in HPLC according to the program described in section 2 . We used the chromatograms of pure compounds for their identification in the grain samples analyzed (Figure S1). For the identification, we used mainly the retention times (ferulic acid $\approx 17 \mathrm{~min} ; \rho$-coumaric acid $\approx 15.2 \mathrm{~min}$; caffeic acid $\approx 11.2 \mathrm{~min}$; vanillic acid $\approx 10.4 \mathrm{~min}$.; syringic acid $\approx 11.7 \mathrm{~min}$ ). In Figure $S 1 \mathrm{~A}$ we showed the chromatogram of a mix of the same amount of each phenolic compound. The area and height at $280 \mathrm{~nm}$ of the monomeric peaks were very similar. This means that the response factor (absorbance by weight unit) was very similar for all pure phenolic compounds studied in this paper. The peaks appearing from minute 19 onwards were considered dimeric phenolics (phenolic compounds all together). We tried to identify the phenolic compounds peaks in the grain samples using retention time, but we found small variations in the compounds peak migrations times and also small unknown peaks near phenolic compounds peaks. In these cases, we used the spectrum of the pure compounds from 210 to $400 \mathrm{~nm}$ and we compare it with the peaks present in the samples (Figure S2) using the tool for detection of pure spectra of the ChemStation software. When the peak spectrum showed no coincidence above $80 \%$ with any of the pure spectra no peak was identified. Moreover, we did not associate the peaks of the dimeric region with any particular phenolic compound and we could not measure the total amount of each individual phenolic compound. We extracted free, bound and soluble-conjugated phenolic compounds from whole flour of a set of Tritordeum lines assayed during three consecutive years. The different fractions of phenolic compounds were injected into liquid chromatograph columns as described in section 2 (Figure 1). In Figure 1A we plot a typical chromatogram of the bound phenolic fraction. This chromatogram presented pCA, FA and dimers. In the fraction of soluble-conjugated phenolics (Figure 1B) we found all phenolic compounds studied in this work (FA, pCA, CA, VA, and SA), although some of them at very low amounts. Finally, the fraction of free phenolics VA, SA, FA, and dimers is presented (Figure 1C).

\subsection{OUANTIFICATION OF PHENOLIC ACID COMPOSITION}

The relative quantification is shown in Table 2 . The values shown are the mean percentages and standard deviation of all lines and 


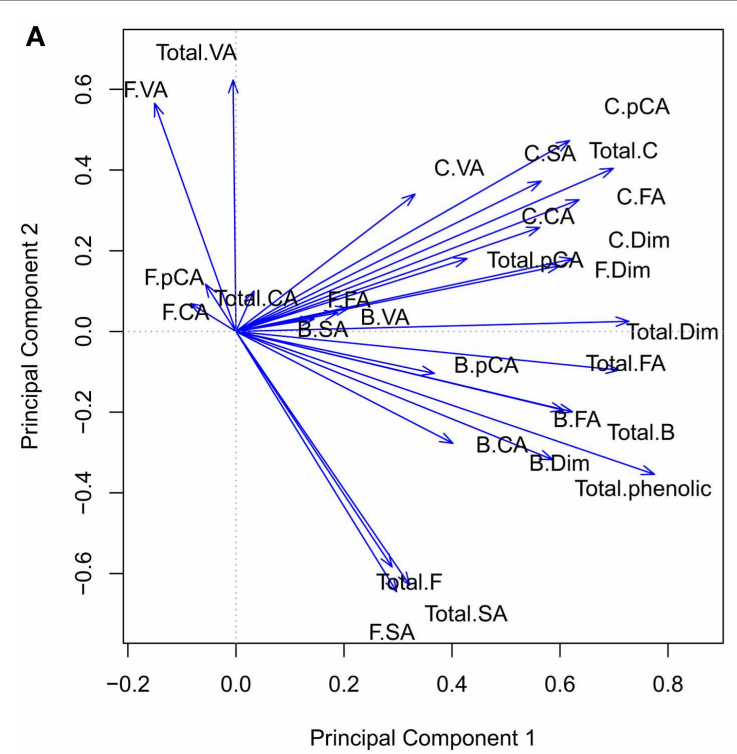

FIGURE 2 | Principal components analysis. (A) The quantitative variables are represented. (B) The individuals lines and the centroids of levels factors "Year," "Sustitutions," "1RS/RL," and "Cytoplasm" are represented.x "B.FA," "F.FA," "C.FA," "Total.FA" are bound, free, conjugated and total ferulic acid; "B.VA," "F.VA," "C.VA," "Total.VA" are bound, free, conjugated and total vanillic acid; "B.pCA," "F.pCA,"

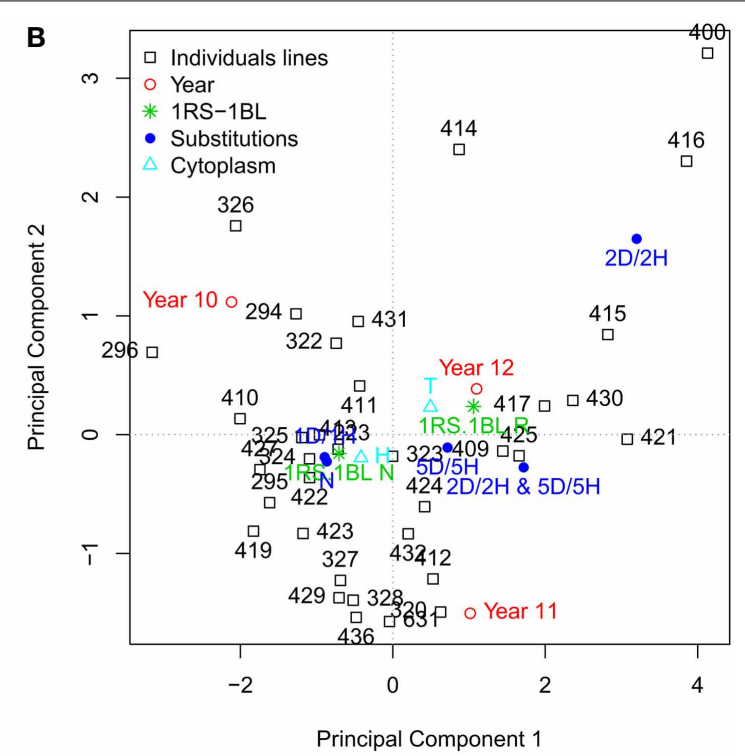

"C.pCA," "Total.pCA" are bound, free, conjugated and total p-coumaric acid; "B.CA," "F.CA," "C.CA," "Total.CA" are bound, free, conjugated and total caffeic acid; "B.SA," "F.SA," "C.SA," "Total.SA" are bound, free, conjugated and total syringic acid; "Total.B," total bound phenolic; "Total.F," total free phenolic; "Total.C," total conjugated phenolic; "Total.phenolic," total phenolic; "Total.Dim," total dimer phenolic. years. The most abundant compound in the fraction of bound phenolics is ferulic acid followed by $\rho$-coumaric. Ferulic acid is also the main compound in the fraction of conjugated phenolics. In the fraction of free phenolics is more abundant syringic acid. In general, the main compound quantitatively is the ferulic acid and the second most abundant is the syringic acid. With respect to the fractions, the highest content of phenolic compounds are in the bound fraction and the lowest in the conjugated.

\subsubsection{Exploratory multivariate analysis (MANOVA and PC) of phenolic compounds content}

We carried out a multivariate analyze to explore the whole data set. We fitted two models because the factor "Line" did not have repetitions inside of each year. Therefore, the Model 1 was: "variable $\sim$ Line + Year". The analysis of variance table showed that "Line" and "Year" had a highly significant effect on the data set (Table S1; Model 1). The Model 2 was fitted with main factors Year, Substitutions, translocation 1RS/1BL, Cytoplasm and the two interactions between them ('variable $\sim$ Year + $1 \mathrm{RS} / 1 \mathrm{BL}+$ Substitutions + Cytoplasm + Year $\times 1 \mathrm{RS} / 1 \mathrm{BL}+$ Year $\times$ Substitutions + Year $\times$ Cytoplasm $+1 \mathrm{RS} / 1 \mathrm{BL} \times$ Substitutions $+1 \mathrm{RS} / 1 \mathrm{BL} \times$ Cytoplasm + Substitutions $\times$ Cytoplasm'). The main factors Year, $1 \mathrm{RS} / 1 \mathrm{BL}$ and Substitutions had a significant effect on the data set (Table S1; Model 2). The interactions Year $\times$ Substitutions and $1 \mathrm{RS} / 1 \mathrm{BL} \times$ Substitutions also showed a significant effect. These results were used to simplify the models for the univariate analysis of each variable.

Principal component analysis (PC), based on correlation matrix, was performed using the different phenolic compounds contents and the factors with significant effects. According to the Kaiser-Harris criterion (Kaiser, 1974) we selected eight components with eigenvalues greater than 1 . We used the principal component analysis as an exploratory analysis and not as a tool to reduce the number of variables. For this reason, we plotted the variables and factors regarding the principal component one and two, which accumulate the higher variability. Most of the variables are correlated with principal component 1 (PC1) being positive for all of them (Figure 2A). The PC2 showed a high correlation with the amounts of free vallinic acid, total vanillic acid, total free phenolic, free and total syringic acid. In this case, the amount of free and total syringic acid had a negative correlation with free vallinic acid, total vanillic acid and total free phenolics. The amount of free $\rho$-coumaric acid, free caffeic acid, bound syringic acid, free ferulic acid, bound vallinic acid and bound syringic acid showed a low correlation with PC1 and PC2.

The factors are represented on the PC1 and PC2 (Figure 2B). The factor "Year" had all its levels spread in the four different quadrants. The year 2011 and 2012 showed some variation along PC2; the year 2010 showed differences with respect to the year 2012 along of the PC1 and with the 2011 in both (PC1 and PC2). The "Substitutions" factor presented a wide dispersion of their levels. Disomic substitution $\operatorname{DS} 2 \mathrm{D}\left(2 \mathrm{H}^{\mathrm{ch}}\right)$ and $\operatorname{DS} 5 \mathrm{D}\left(5 \mathrm{H}^{\mathrm{ch}}\right)$ showed the higher differences regarding to the "no substitution" level, mainly along PC1. Disomic substitution $\mathrm{DS} 2 \mathrm{D}\left(2 \mathrm{H}^{\mathrm{ch}}\right)$ showed the greatest differences regarding to the level "no substitutions" along both PC1 and PC2. The two levels of the factor "1RS/1BL" translocation showed difference in PC1. The "Line" factor showed a wide dispersion, although there is some accumulation in quadrant $3(-,-)$, where 
Table 3 | Table with the percentage of variance explained by each factors, derived from the ANOVA table of Model 1 ('variable $\sim$ Line + Year').

\begin{tabular}{|c|c|c|c|}
\hline \multirow[t]{2}{*}{ Model 1} & \multicolumn{3}{|c|}{ SS percentage } \\
\hline & $\begin{array}{c}\text { Line } \\
(\mathrm{Df}=36)\end{array}$ & $\begin{array}{c}\text { Year } \\
(D f=2)\end{array}$ & $\begin{array}{l}\text { Residuals } \\
\text { (Df = 72) }\end{array}$ \\
\hline Total ferulic acid & $33.51 * *$ & $37.21^{*}$ & 29.28 \\
\hline Conjugated ferulic acid & 29.70 & $25.73^{*}$ & 44.57 \\
\hline Free ferulic acid & $56.25^{*}$ & 0.04 & 43.71 \\
\hline Bound ferulic acid & $36.02 * *$ & $32.36^{*}$ & 31.63 \\
\hline Total vanillic acid & 30.78 & $25.47^{*}$ & 43.74 \\
\hline Conjugated vanillic acid & $42.07^{*}$ & $7.71 * *$ & 50.22 \\
\hline Total $\rho$-coumaric acid & $31.11 *$ & $35.29 *$ & 33.60 \\
\hline Conjugated $\rho$-coumaric acid & $40.79 *$ & $33.34^{*}$ & 25.87 \\
\hline Free $\rho$-coumaric acid & $53.76^{*}$ & $10.61^{*}$ & 35.62 \\
\hline Bound $\rho$-coumaric acid & 28.44 & $34.06^{*}$ & 37.51 \\
\hline Total syringic acid & $39.96^{*}$ & $35.68^{*}$ & 24.36 \\
\hline Conjugated syringic acid & $49.18 * *$ & 1.21 & 49.61 \\
\hline Free syringic acid & $40.25^{*}$ & $35.32^{*}$ & 24.43 \\
\hline Total caffeic acid & 36.76. & $12.51^{*}$ & 50.73 \\
\hline Conjugted caffeic acid & $45.91 * *$ & $8.41 * *$ & 45.67 \\
\hline Total bound & $33.49 * *$ & $33.82^{*}$ & 32.70 \\
\hline Total free & $37.34 *$ & $35.35^{*}$ & 27.31 \\
\hline Total conjugated & 34.06. & $21.59^{*}$ & 44.34 \\
\hline Total phenolic acids & $28.21 *$ & $41.25^{*}$ & 30.54 \\
\hline Total dimers & $56.69 *$ & $8.22^{*}$ & 35.10 \\
\hline Conjugated dimers & $39.29 *$ & $15.05^{*}$ & 45.66 \\
\hline Free dimers & $57.64^{*}$ & 2.04 & 40.32 \\
\hline Bound dimers & $46.40^{*}$ & $17.35^{*}$ & 36.25 \\
\hline
\end{tabular}

SS, sum of the squared; $D f$, degree of freedom.

Significant codes: 0 "***," 0.001 "**," 0.01 "*," 0.05 .," 0.1 "."

the control levels of factors "Substitutions" and "1RS/1BL" are found.

\subsubsection{Univariate analysis of phenolic compounds content}

We carried out a univariate analysis of variance to check which variables were affected by the factors studied. We fitted two models for the same reason that in the multivariate analysis of variance. Moreover, the MANOVA Model 1 and 2 showed factors with significant effects, consequently, we conducted univariate analysis of each of the variables using both models. In MANOVA Model 1 all factors, "Line" and "Year," were significant, for that reason we use the same model ('variable $\sim$ Line + Year'). In this analysis the factor "Line" had a significant effect (with a $p$ value $<0.05$ ) for all variables except conjugated FA, total VA, bound pCA, total CA and total conjugated (Table 3). The percentage of variance explained by the factor "Line" range between $57.6 \%$ and $28.2 \%$. The factor "Year" had a significant effect on all variables except free FA, conjugated SA and free dimers. The percentage of variance explained by the factor "Year" range between $41.2 \%$ and $7.71 \%$.

From the results of MANOVA Model 2, we simplified the model by eliminating terms that were not significant. Therefore, we used the following Model 2 in the univariate analysis: "variable $\sim$ Year + Substitutions +1 RS/1BL + Year $\times$ Substitutions + Substitutions $\times 1 \mathrm{RS} / \mathrm{BL}$ ". In this model the factor "Year" showed behavior almost identical to that shown in Model 1, showing even a very similar explained variance (Table 4). The factor "Substitution" showed a significant effect for all variables except bound pCA, total SA, free SA, total bound and total free. The variance explained by the factor "Substitution" ranged from $5.8 \%$ to $32.6 \%$ of the total variance. The factor " $1 \mathrm{RS} / 1 \mathrm{BL}$ " had a significant effect on total FA, conjugated FA, bound FA, bound pCA and total bound. The percentage of variance explained by this factor ranged from $2.2 \%$ to $3.6 \%$. Interaction "Year $\times$ Substitutions" had significant effects on the variables conjugated FA, total conjugated and conjugated dimers, with percentages of explained variances from $15.8 \%$ to $18.7 \%$. The last terms of Model 2, the interaction of "Substitution $\times 1 \mathrm{RS} / 1 \mathrm{BL}$ " showed a significant effect for the variables total FA, bound FA, conjugated $\mathrm{VA}$, total $\mathrm{pCA}$, conjugated $\mathrm{pCA}$, free $\mathrm{pCA}$, conjugated SA and conjugated CA. The percentages of variance explained by this interaction are between $3.3 \%$ and $10.0 \%$. The factor " $1 \mathrm{RS} / 1 \mathrm{BL}$ " as shown in Figure 3 increased the FA content in general,(solubleconjugate, bound and total ferulic), bound pCA and total bound phenolics.

For the factor "Substitution" we carried out a comparison of means between the different levels (Figure 4). Chromosome substitution $\operatorname{DS} 1 \mathrm{D}\left(1 \mathrm{H}^{\mathrm{ch}}\right)$ caused an increase of total pCA. The substitution DS2D $\left(2 \mathrm{H}^{\text {ch }}\right)$ was the substitution with the higher effect on phenolic compounds. This substitution increased total pCA, conjugated $\mathrm{pCA}$, conjugated $\mathrm{CA}$, total dimers and free dimers. In fact, three of the four lines with the highest contents of phenolic compounds had the substitution DS2D $\left(2 \mathrm{H}^{\text {ch }}\right)$ (lines 400,415 , and 416).

\section{DISCUSSION}

Phenolic compounds of whole grain are an important trait because they have several human health benefits. Wild cereal species are an important source of variability that can be used by plant breeders to produce healthier wheat varieties. The amphiploid tritrodeum is an excellent way to access the variability present in the wild species $H$. chilense. In this paper we characterize the phenolic acid composition of a collection of tritordeums, and we assess the effect of growing season, the barley or wheat cytoplasm, chromosomal substitutions and the widespread chromosomal translocation 1RS/1BL.

Until now, there was little information on the composition of phenolic acids, the main compounds with antioxidant activity, of the amphiploid tritordeum. Ferulic acid is the predominant phenolic acid found in whole grains (Krygier et al., 1982; Mattila et al., 2005) and whole wheat (Moore et al., 2005; Li et al., 2008). These authors have reported ferulic acid percentages to the total of phenolic compounds in the range of $72-85 \%$, in the case of $\mathrm{Li}$ et al. (2008) and 83.5-89.5\% in the case of Moore et al. (2005). The percentages of ferulic acid with respect to total phenolics in our tritordeum collection (on average 76.38\%) are similar to those found in wheat. In our study, $90.2 \%$ of total ferulic acid is found in the fraction of bound phenolic acids. These values agree with those reported in wheat, since several authors have shown 
Table 4 | Table with the percentage of variance explained by each factors, derived from the ANOVA table of Model 2 ('variable $\sim$ Year + Substitutions + 1RS/1BL + Year $\times$ Substitutions + Substitutions $\left.\times 1 R S / B L^{\prime}\right)$.

Model 2

SS percentage

\begin{tabular}{|c|c|c|c|c|c|}
\hline $\begin{array}{c}\text { Year } \\
\text { (Df = 2) }\end{array}$ & $\begin{array}{l}\text { Substitutions } \\
\qquad(\mathrm{Df}=4)\end{array}$ & $\begin{array}{l}\text { 1RS/1BL } \\
(\mathrm{Df}=1)\end{array}$ & $\begin{array}{c}\text { Year x Subs. } \\
\quad(\text { Df }=8)\end{array}$ & $\begin{array}{c}\text { Subs. } \times 1 R S / 1 B L \\
(D f=2)\end{array}$ & $\begin{array}{r}\text { Residuals } \\
\text { (Df }=90 \text { ) }\end{array}$ \\
\hline $38.85^{*}$ & $6.92^{*}$ & $3.02 *$ & 1.68 & $3.29 *$ & 46.24 \\
\hline $25.54^{*}$ & $12.30 *$ & $2.18^{*}$ & $18.70 *$ & 0.31 & 40.97 \\
\hline 0.23 & $14.49 * *$ & 2.73 & 3.41 & 3.24 & 75.90 \\
\hline $33.41 *$ & $5.90 *$ & $3.02 *$ & 1.43 & $4.04^{*}$ & 52.21 \\
\hline $27.59 *$ & $6.51 *$ & 0.19 & 7.94 & 1.90 & 55.88 \\
\hline $8.10^{* *}$ & $10.63^{* *}$ & 0.82 & 6.49 & $10.03^{* *}$ & 63.93 \\
\hline $33.58 *$ & $6.43^{*}$ & 2.11 & 6.07 & $3.66^{*}$ & 48.15 \\
\hline $37.39 *$ & $14.79 *$ & 0.33 & 2.29 & $5.74 * *$ & 39.46 \\
\hline $10.83^{* *}$ & $10.12^{*}$ & 0.14 & 4.33 & $6.93^{*}$ & 67.65 \\
\hline $32.70^{*}$ & 3.48 & $2.88^{*}$ & 1.51 & 2.17 & 57.26 \\
\hline $35.58 *$ & 1.27 & 0.07 & 2.87 & 0.27 & 59.95 \\
\hline 1.01 & $22.86^{*}$ & 0.25 & 3.55 & $8.63^{* *}$ & 63.69 \\
\hline $34.96 *$ & 1.04 & 0.04 & 3.08 & 0.30 & 60.58 \\
\hline $12.53^{*}$ & $10.36^{*}$ & 0.06 & 2.37 & 2.52 & 72.16 \\
\hline $8.82^{* *}$ & $17.67 *$ & 0.02 & 4.28 & $8.45^{* *}$ & 60.76 \\
\hline $34.88 *$ & 4.91 & $3.62 *$ & 1.17 & 3.15 & 52.27 \\
\hline $34.63^{*}$ & 3.30 & 0.25 & 2.59 & 0.59 & 58.63 \\
\hline $21.78 *$ & $16.05^{*}$ & 1.18 & $15.83^{*}$ & 1.04 & 44.12 \\
\hline $42.66^{*}$ & $5.79 *$ & 1.48 . & 0.83 & 1.81 & 47.43 \\
\hline $8.96 *$ & $31.34 *$ & 0.23 & 3.28 & 3.32 . & 52.87 \\
\hline $15.70 *$ & $9.78^{* *}$ & 2.21 & $16.30 * *$ & 0.43 & 55.58 \\
\hline 2.17 & $32.64^{*}$ & 0.00 & 4.35 & 2.57 & 58.26 \\
\hline $18.91 *$ & $17.49 *$ & 0.36 & 3.31 & 3.41 & 56.52 \\
\hline
\end{tabular}

SS, sum of the squared; Df, degree of freedom.

Significant codes: 0 "***," 0.001 "**," 0.01 "*, $0.05 ., " 0.1$ "."
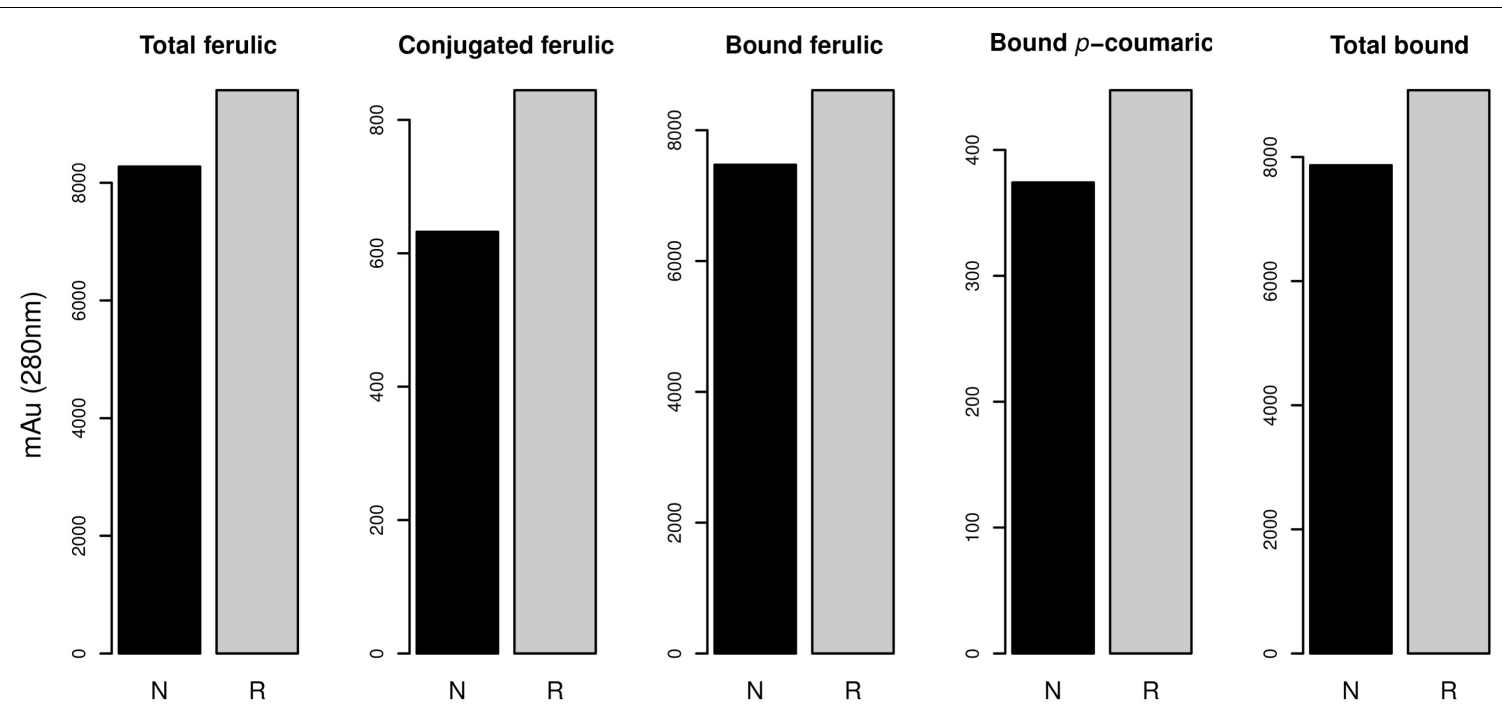

FIGURE 3 | Content of phenolic compounds with a significant effect of the translocation 1RS/RL ( $p$-value < 0.05; Table 4). N, no translocation; $\mathrm{R}$ translocation $1 \mathrm{RS} / \mathrm{RL}$. 


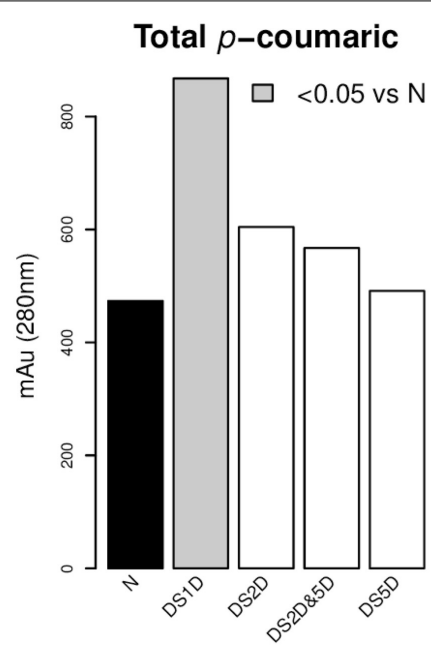

Total dimers

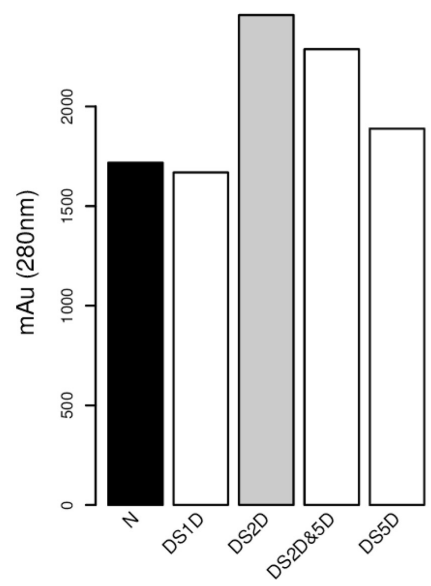

Conjugated $p$-coumaric

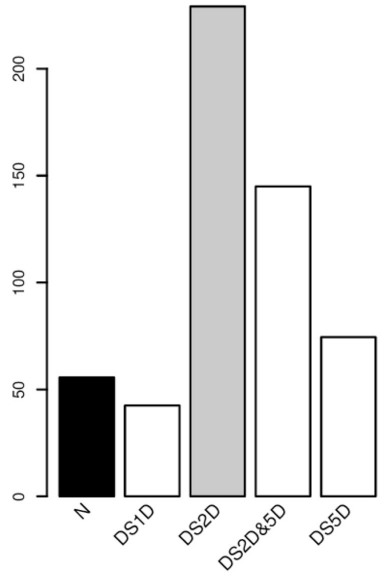

Free dimers

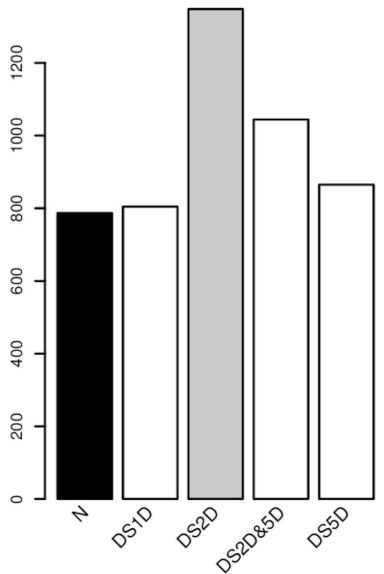

\section{Conjugated caffeic}

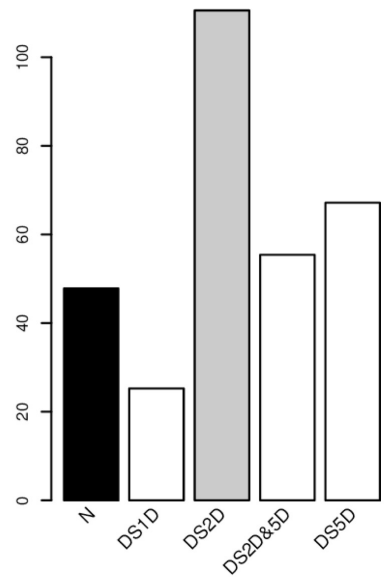

FIGURE 4 | Phenolic acid content and multiple-comparison results of the different substitution lines. Gray bars are significantly different ( $p$-value $<0.05$ ) compared to the no substitution (N). Comparison of means (Tukey contrast) between levels of factor "Substitutions" took place only when the ANOVA table of Model 2 (Table 4) showed a significant effect of this factor. Figure shows only those compounds where any substitution level showed differences with respect to no substitution level (N). percentages of ferulic acid in the bound fraction from $89 \%$ to $97 \%$ (Adom et al., 2003; Moore et al., 2005; Li et al., 2008).

Other phenolic acids were also found in significant quantities in whole wheat. Okarter et al. (2010) have reported that the second most abundant phenolic acid found in whole wheat is $\rho$ coumaric acid. In this study, the second more abundant phenolic compound is the syringic acid and not the $\rho$-coumaric acid, which was found in smaller amounts than syringic acid (16.6\% of total phenolic acids is syringic acid and only the $4.52 \%$ of total phenolics is $\rho$-coumaric acid). The higher ratio of syringic acid in grain has been also reported by Li et al. (2008) in spring and spelt wheat and some varieties of soft wheat (Moore et al., 2005).

Syringic and vanillic acids are hydroxybenzoic acids, and ferulic acid, $\rho$-coumaric acid and caffeic are hydroxyninnamic. The hydroxyninnamic and hydroxybenzoic acids belong to different biosynthetic pathways; hydroxybenzoic acids belong to aminobenzoate pathway, and the hydroxyninnamic acids to the phenylpropanoid biosynthesis pathway. Figure 2A shows a high correlation of the total hydroxybenzoic acids (total vanillic acid syringic total acid) with PC2, unlike most hydroxyninnamic acids (ferulic acid, caffeic acid and $\rho$-coumaric acids) are correlated with PC1. This may be because the hydroxybenzoic acids and hydroxyninnamic acids belong to different pathway and these pathways are not strongly correlated.

Several authors have shown high and positive correlations between total free, conjugated and bound phenolic acids (Verma et al., 2008; Fernandez-Orozco et al., 2010). In our study there is a strong correlation between total conjugated and united phenolic. On the contrary, the total free phenolics is less correlated with the above (total bound and conjugated phenolics) in contrast to that reported by Fernandez-Orozco et al. (2010). Syringic acid is the compound with mayor contribution to the total free phenolics, while ferulic acid is the main phenolic compound of bound and conjugated phenolics. The low correlation observed between the free phenolics with conjugated and bound phenolics may be due to that the ferulic acid and syringic acid 
belong to different biosynthetic pathways, as we have described above.

The environmental effect (the growing season and location) has been proposed as the main factor that determines phenolic acid content. Environmental factors such as solar radiation, temperature, and irrigation, affect the content of phenolic acids in wheat but some phenolics fractions are more susceptible to the effect of environment than others (Moore et al., 2006; FernandezOrozco et al., 2010). Mpofu et al. (2006) has shown that the effect of the environment is greater than the effect of genotype on hard and spring wheat. Our study corroborates the fact that the environment has a strong effect on the content of phenolic acids, as shows the effect of the factor "Year" in our analysis. Conversely, our study shows that although the effect of the environment is high the genotype has a greater effect in many of the analyzed phenolics fractions. In fact, the factor "Year" only had a greater impact than genotype on the total ferulic acid, total $\rho$-coumeric, bound $\rho$-coumeric and total phenolic. Our study shows a greater effect of factor "genotype" that has not been previously shown in wheat. This may be due to the higher genetic variability of tritordeum in comparison to wheat. This variability gives amphiploid tritrordeum a high value as source of genetic variability to improve the antioxidant content of wheat, or as a cereal food crop in its own right.

As shown in Figure 4, the chromosome substitution $\operatorname{DS} 2 \mathrm{D}\left(2 \mathrm{H}^{\mathrm{ch}}\right)$ increases the content of hydroxyninnamic acids (caffeic acid and $\rho$-coumaric acids). We also observed an effect on the phenolic acid content of the substitution $\operatorname{DS} 1 \mathrm{D}\left(1 \mathrm{H}^{\mathrm{ch}}\right)$, since it increases the total dimers. This suggest that either the absence of chromosome $2 \mathrm{H}^{\text {ch }}$ or the introgression of chromosome $2 \mathrm{D}$ leads to increase the content of phenolic compounds. The widely used translocation $1 \mathrm{RS} / 1 \mathrm{BL}$ increases the content of total, conjugated and bound ferulic acid, bound $\rho$-coumaric acid and total bound phenolics in tritordeum. This is the first work where the phenolic acid content is associated with the substitution of chromosome $\operatorname{DS} 1 \mathrm{D}\left(1 \mathrm{H}^{\mathrm{ch}}\right)$ and $\mathrm{DS} 2 \mathrm{D}\left(2 \mathrm{H}^{\mathrm{ch}}\right)$, and the translocation $1 \mathrm{RS} / 1 \mathrm{BL}$ in tritordeum. Therefore, on chromosome 1 and 2 may be located genes involved in hydroxyninnamic acids biosynthesis and/or accumulation.

In conclusion, the high variability of phenolic compounds present in tritordeum confers this a high potential for improving the quality and quantity of dietary antioxidants in cereals. However, in this connection, some limitations are worth noting. The transfer of traits from wild relative species to wheat can be achieved by uncontrolled translocations which may also introduce non-desired traits, or by the identification of genes involved in the trait and its use for wheat transformation. Thus, although tritordeum is very interesting source of genetic variability for phenolic acid content more in depth understanding of the genes that determine the content of phenolic compounds is needed for directed improvement of antioxidants in tritordeum or in related cereals.

\section{FUNDING}

This work was supported by the Spanish Comisión Interministerial de Ciencia y Tecnología (AGL2011-22596). FP is supported by "Ramón y Cajal" research contract from the MINECO (RYC-2010-07345).

\section{ACKNOWLEDGMENTS}

The authors thank Carmen Ramirez for her dedication to the development and care of the plant material used in this work. The authors thank Dr. Paul A. Lazzeri for his critical review of the manuscript.

\section{SUPPLEMENTARY MATERIAL}

The Supplementary Material for this article can be found online at: http://www.frontiersin.org/journal/10.3389/fpls.2014.00010/ abstract

Table S1 | ANOVAs tables from the MANOVA analysis of the Model 1 ('variable $\sim$ Line + Year') and Model 2 ('variable $\sim$ Year + 1RS/1BL + Substitutions + Cytoplasm + Year $\times 1$ RS/1BL + Year $\times$ Substitutions + Year $\times$ Cytoplasm $+1 \mathrm{RS} / 1 \mathrm{BL} \times$ Substitutions $+1 \mathrm{RS} / 1 \mathrm{BL} \times$ Cytoplasm + Substitutions $\times$ Cytoplasm').

Figure S1 | RP-HPLC chromatograms of the pure phenolic compounds studied in this work. For this analysis we used pure phenolics from SIGMA-ALDRICH. Mix, a mix of the same amount of each phenolic acids. FA, ferulic acid; pCA, $\rho$-coumaric acid; CA, caffeic acid;VA, vanillic acid; SA, syringic acid.

\section{Figure S2 | Spectra of the pure phenolic acids.}

\section{REFERENCES}

Adom, K. K., Sorrells, M. E., and Liu, R. H. (2003). Phytochemical profiles and antioxidant activity of wheat varieties. J. Agric. Food Chem. 51, 7825-7834. doi: 10.1021/jf0304041

Atienza, S. G., Ballesteros, J., Martín, A., and Hornero-Méndez, D. (2007). Genetic variability of carotenoid concentration and degree of esterification among tritordeum ( $x$ Tritordeum Ascherson et Graebner) and durum wheat accessions. J. Agric. Food Chem. 55, 4244-4251. doi: 10.1021/ jf070342p

Beta, T., Nam, S., Dexter, J. E., and Sapirstein, H. D. (2005). Phenolic content and antioxidant activity of pearled wheat and roller-milled fractions. Cereal Chem. 82, 390-393. doi: 10.1094/CC-82-0390

Castillo, A., Ramírez, M. C., Martín, A. C., Kilian, A., Martín, A., and Atienza, S. G. (2013). High-throughput genotyping of wheat-barley amphiploids utilising diversity array technology (DArT). BMC Plant Biology 13:87. doi: 10.1186/14712229-13-87

de Munter, J. S. L., Hu, F. B., Spiegelman, D., Franz, M., and van Dam, R. M. (2007). Whole grain, bran, and germ intake and risk of type 2 diabetes: a prospective cohort study and systematic review. PLoS Med. 4:e261. doi: 10.1371/journal.pmed.0040261

Fernandez-Orozco, R., Li, L., Harflett, C., Shewry, P. R., and Ward, J. L. (2010). Effects of environment and genotype on phenolic acids in wheat in the HEALTHGRAIN diversity screen. J. Agric. Food Chem. 58, 9341-9352. doi: $10.1021 /$ jf102017s

Flight, I., and Clifton, P. (2006). Cereal grains and legumes in the prevention of coronary heart disease and stroke: a review of the literature. Eur. J. Clin. Nutr. 60, 1145-1159. doi: 10.1038/sj.ejcn.1602435

Fox, J., and Weisberg, S. (2011). An R Companion to Applied Regression, 2nd Edn. Thousand Oaks, CA: Sage.

Hothorn, T., Bretz, F., and Westfall, P. (2008). Simultaneous inference in general parametric models. Biom. J. 50, 346-363. doi: 10.1002/bimj.200810425

Husson, F., Josse, J., Le, S., and Mazet, J. (2013). FactoMineR: Multivariate Exploratory Data Analysis and Data Mining with R. R package version 1.25. Available online at: http://CRAN.R-project.org/package=FactoMineR

Irakli, M. N., Samanidou, V. F., Biliaderis, C. G., and Papadoyannis, I. N. (2012). Development and validation of an HPLC-method for determination of free and bound phenolic acids in cereals after solid-phase extraction. Food Chem. 134, 1624-1632. doi: 10.1016/j.foodchem.2012.03.046

Jonnalagadda, S. S., Harnack, L., Liu, R. H., McKeown, N., Seal, C., Liu, S., et al. (2011). Putting the whole grain puzzle together: health benefits associated with whole grains-summary of American Society for Nutrition 2010 satellite symposium. J. Nutr. 141, 1011S-1022S. doi: 10. 3945/jn.110.132944

Kaiser, H. F. (1974). An index of factorial simplicity. Psychometrika 39, 31-36. doi: 10.1007/BF02291575 
Krygier, K., Sosulski, F., and Hogge, L. (1982). Free, esterified, and insoluble-bound phenolic acids. 1. extraction and purification procedure. J. Agric. Food Chem. 30, 330-334. doi: 10.1021/jf00110a028

Lewin-Koh, N. J., Bivand, R., Pebesma, C. B. E. J., Archer, E., Baddeley, A., Bibiko, H.-J., et al. (2012). Maptools: Tools for Reading and Handling Spatial Objects. R package version 0.8-14. Available online at: http://CRAN.Rproject.org $/$ package $=$ maptools

Li, L., Shewry, P. R., and Ward, J. L. (2008). Phenolic acids in wheat varieties in the HEALTHGRAIN diversity screen. J. Agric. Food Chem. 56, 9732-9739. doi: $10.1021 /$ jf801069s

Marquardt, L., Asp, N. G., Richardson, P., Kamp, J. W., Asp, N. G., Miller Jones, J., et al. (2004). "Whole grain health claims in the United States, United Kingdom and Sweden," in Dietary Fibre-Bioactive Carbohydrates in Food and Feed, eds J. W. van der Kam, N. G. Asp, J. Miller Jones, and G. Schaafsma (Wageningen: Wageningen Academic Publishers), 39-57.

Martin, A., and Sanchez-Mongelaguna, E. (1982). Cytology and morphology of the amphiploid Hordeum chilense $\times$ Triticum turgidum conv. Durum. Euphytica 31, 261-267. doi: 10.1007/BF00028329

Martín, A., Alvarez, J., Martín, L., Barro, F., and Ballesteros, J. (1999). The development of tritordeum: a novel cereal for food processing. J. Cereal Sci. 30, 85-95. doi: $10.1006 /$ jcrs. 1998.0235

Martín, A., Martin, L. M., Cabrera, A., Ramirez, M. C., Gimenez, M. J., Rubiales, D., et al. (1998). The potential of Hordeum chilense in breeding triticeae species. Triticeae III, 377-386.

Mattila, P., Pihlava, J.-M., and Hellström, J. (2005). Contents of phenolic acids, alkyl- and alkenylresorcinols, and avenanthramides in commercial grain products. J. Agric. Food Chem. 53, 8290-8295. doi: 10.1021/jf051437z

Mellado-Ortega, E., and Hornero-Méndez, D. (2012). Isolation and identification of lutein esters, including their regioisomers, in tritordeum ( $\times$ Tritordeum Ascherson et Graebner) grains: evidence for a preferential xanthophyll acyltransferase activity. Food Chem. 135, 1344-1352. doi: 10.1016/j.foodchem.2012.05.046

Moore, J., Hao, Z., Zhou, K., Luther, M., Costa, J., and Yu, L. L. (2005). Carotenoid, tocopherol, phenolic acid, and antioxidant properties of maryland-grown soft wheat. J. Agric. Food Chem. 53, 6649-6657. doi: 10.1021/jf050481b

Moore, J., Liu, J.-G., Zhou, K., and Yu, L. L. (2006). Effects of genotype and environment on the antioxidant properties of hard winter wheat bran. J. Agric. Food Chem. 54, 5313-5322. doi: 10.1021/jf0603811

Mpofu, A., Sapirstein, H. D., and Beta, T. (2006). Genotype and environmental variation in phenolic content, phenolic acid composition, and antioxidant activity of hard spring wheat. J. Agric. Food Chem. 54, 1265-1270. doi: $10.1021 /$ jf052683d
Okarter, N., Liu, C.-S., Sorrells, M. E., and Liu, R. H. (2010). Phytochemical content and antioxidant activity of six diverse varieties of whole wheat. Food Chem. 119, 249-257. doi: 10.1016/j.foodchem.2009.06.021

R Development Core Team. (2012). R: A Language and Environment for Statistical Computing. Vienna, Austria: R Foundation for Statistical Computing. ISBN $3-$ 900051-07-0.

Shewry, P. R., Piironen, V., Lampi, A.-M., Edelmann, M., Kariluoto, S., Nurmi, T., et al. (2010). The HEALTHGRAIN wheat diversity screen: effects of genotype and environment on phytochemicals and dietary fiber components. J. Agric. Food Chem. 58, 9291-9298. doi: 10.1021/jf100039b

Verma, B., Hucl, P., and Chibbar, R. N. (2008). Phenolic content and antioxidant properties of bran in 51 wheat cultivars. Cereal Chem. 85, 544-549. doi: 10.1094/CCHEM-85-4-0544

Yu, L., and Zhou, K. (2005). Antioxidant properties of bran extracts from 'Platte' wheat grown at different locations. Food Chem. 90, 311-316. doi: 10.1016/j.foodchem.2004.04.007

Zhou, K., Su, L., and Yu, L. L. (2004). Phytochemicals and antioxidant properties in wheat bran. J. Agric. Food Chem. 52, 6108-6114. doi: 10.1021/jf049214g

Zhou, K., Yin, J.-J., and Yu, L. L. (2005). Phenolic acid, tocopherol and carotenoid compositions, and antioxidant functions of hard red winter wheat bran. $J$. Agric. Food Chem. 53, 3916-3922. doi: 10.1021/jf050117c

Conflict of Interest Statement: The authors declare that the research was conducted in the absence of any commercial or financial relationships that could be construed as a potential conflict of interest.

Received: 31 October 2013; accepted: 07 January 2014; published online: 30 January 2014.

Citation: Navas-Lopez JF, Ostos-Garrido FJ, Castillo A, Martín A, Gimenez MJ and Pistón F (2014) Phenolic content variability and its chromosome location in tritordeum. Front. Plant Sci. 5:10. doi: 10.3389/fpls.2014.00010

This article was submitted to Crop Science and Horticulture, a section of the journal Frontiers in Plant Science.

Copyright (C) 2014 Navas-Lopez, Ostos-Garrido, Castillo, Martin, Gimenez and Piston. This is an open-access article distributed under the terms of the Creative Commons Attribution License (CC BY). The use, distribution or reproduction in other forums is permitted, provided the original author(s) or licensor are credited and that the original publication in this journal is cited, in accordance with accepted academic practice. No use, distribution or reproduction is permitted which does not comply with these terms. 